\title{
THE THERMODYNAMIC DIAGRAMS FOR PHASE EQUILIBRIUM OF SYSTEMS ESSENTIAL OIL OF DILL - WATER AND DETERMINATION OF HEIGHT FOR COHOBATION COLUMN
}

\author{
Milen Dimov ${ }^{1}$, Stanislava Tasheva ${ }^{2}$, Krasimira Dobreva $^{1}$, Albena Stoyanova $^{2}$ \\ ${ }^{1}$ Trakia University, Faculty of Technics and Technologies, \\ 38 Graf Ignatiev Str., 8600 Yambol, Bulgaria \\ phone/ mobile: +359877089335, e-mail: midimow@abv.bg \\ ${ }^{2}$ University of Food Technologies, Technological Faculty \\ 26 Maritza Blvd., 4003 Plovdiv, Bulgaria
}

\begin{abstract}
The thermodynamic diagrams for the systems water essential oil from dill (fruits and leaves) were drawn. Equations were derived by which the vapor phase at certain liquid phase can be calculated for the essential oil-water systems mentioned above. Using the McCabe - Thiele graphic analytical method, the theoretical and actual number of trays for a cohobation column processing distillation waters from dill was calculated. The calculations were carried out for three concentrations of the dill distillation waters fed into the column - minimal, average and maximal. The height of the cohobation column for processing dill distillation waters was determined.
\end{abstract}

Keywords: dill, essential oils, chemical composition, cohobation column.

\section{INTRODUCTION}

The mass exchange processes of rectification are widely used in various fields of industry. Rectification is a process of separation of liquid mixtures on the basis of the different volatilities of its components and as results of the countercurrent interaction between vapor and liquid phases. In essential oil industry, it is used to isolate aromatic components from essential oils, purification of essential oils as well their fractionation $[2,7,10,11,12,17]$.

By the distillation of an essential oil from raw material with water vapor, it is assumed that the essential oil and water are mutually insoluble and the essential oil has one component, in some cases two components [13].

During rectification and distillation, part of the aromatic substances present in the liquid phase pass into the vapor phase while others - from vapor to liquid phase.

Various essential oil raw materials are subjected to distillation (either vapor or liquid one) on industrial scale. The extraction of the oil from the raw material gives primary essential oil and primary distillation water. The primary distillation waters contain certain amount essential oil which has been carried mechanically away, emulsified and dissolved. It can be extracted by a process of secondary distillation (cohobation) [14, 17].

By cohobation, according to the first law of Konovalov, the vapor phase is rich in the easily volatile component - the essential oil and its concentration on the vapor phase is several times higher than that in the distillation waters [3].

Many Bulgarian authors calculated the number of theoretical trays necessary to determine the height of the cohobation column for the processing of various essential oil sources. [1, 15, 16].

Dill (Anethum graveolens L.) is an annual grassy herb of the family Apiaceae. The essential oil is secreted in channels in all parts of the plant: stem $10-20 \mathrm{~g} \cdot \mathrm{kg}^{-1}$, leaves $1-5 \mathrm{~g} \cdot \mathrm{kg}^{-1}$, umbels by buttoning and flowering $12-20 \mathrm{~g}^{\mathrm{kg}} \mathrm{g}^{-1}$, fruits $30-60 \mathrm{~g}^{\mathrm{kg}} \mathrm{kg}^{-1}$. The oil is used in cosmetics, food industry and medicine $[3,14]$. 


\section{AR'IIE} Ipplied Researrches in Technics, Technologies and Educiation Journal of the Faculty of Technics and Technologies, Trakia University https://sites.google.com/a/trakia-uni.bg/artte/

\section{MATERIALS AND METHODS}

The thermodynamic equilibrium diagrams for the systems essential oil - water were drawn by a method described in the literature $[2,6,15]$.

To calculate the diagrams, the values of the main components of the essential oils extracted from dill grass and fruits were used [4]:

- for dill grass-carvone (34,51\%), limonene $(21,02 \%)$, p-cymene $(17,59 \%)$, a-phellandrene $(19,69 \%)$ and dehydrocarvone $(7,17 \%)$.

- for dill fruits: limonene $(35,79 \%)$, carvone $(57,98 \%)$ and p-cymene $(6,22 \%)$.

For the drawing of the thermodynamic equilibrium diagrams essential oil - water at certain pressure, the boiling temperatures of the components were taken from literary sources [3].

The cohobation columns operate under atmospheric pressure so the values for water were taken at that pressure [8].

The calculation of an experimental cohobation column was carried out using parameters reported in the literature [15]. The concentration of the essential oil in the distillation waters were also taken from literary sources [14]. Table 1 shows the molar concentration of the incoming distillation waters and the distillate obtained. The concentration of the cube residue in the distillation waters with different initial concentration studied was assumed to be $x_{W}=$ 0,0001 for the grass and fruit oils.

The graphic analytical method of McCabe - Thiele was used to determine the necessary number of trays in the column $[2,5,9,12,13]$.

Table 1. Molar concentration of the incoming distillation waters, the distillate and the cube residue

\begin{tabular}{|l|c|c|c|}
\hline \multicolumn{1}{|c|}{ Denotation } & $\begin{array}{c}\text { Minimal } \\
\text { concentration. } \\
\% \mathrm{~mol}\end{array}$ & $\begin{array}{c}\text { Medium } \\
\text { concentration } \\
\% \mathrm{~mol}\end{array}$ & $\begin{array}{c}\text { Maximal } \\
\text { concentration } \\
\% \mathrm{~mol}\end{array}$ \\
\hline \multicolumn{4}{|c|}{ Dill grass } \\
\hline $\mathrm{X}_{\mathrm{F}}{ }^{*}$ & 0,039 & 0,062 & 0,084 \\
\hline $\mathrm{X}_{\mathrm{D}}{ }^{* *}$ & 0,305 & 0,465 & 0,632 \\
\hline \multicolumn{5}{|c|}{ Dill fruits } \\
\hline $\mathrm{X}_{\mathrm{F}}{ }^{*}$ & 0,039 & 0,059 & 0,079 \\
\hline $\mathrm{X}_{\mathrm{D}}{ }^{* *}$ & 0,290 & 0,442 & 0,594 \\
\hline
\end{tabular}

${ }^{*}$ - concentration of the incoming distillation waters; ${ }^{* *}$-concentration of distillate.

After drawing the working straight line by the graphic analytical method of McCabe - Thiele, the step-shaped line for the determination of the theoretical number of trays was drawn.

The actual number of trays was calculated by equation $(1)[2,13]$ :

$$
n_{D}=\frac{n_{T}}{\eta}
$$

The value of the coefficient of efficiency can be determined precisely enough from experimental data only. Usually, the coefficient of efficiency of the trays is within the range 0,2-0,9 [2, 13].

The height of the cohobation column was calculated by equation (2) [12]:

$$
\mathrm{H}=\mathrm{H}_{1}+\mathrm{H}_{2}+\mathrm{H}_{3}+\left(\mathrm{n}_{\mathrm{r}}-1\right) \cdot h
$$




\section{IRITIE}

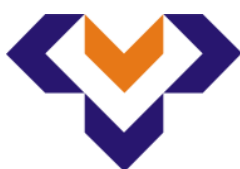

Ipplied Reseirl'ches in Technics, Technologies and Bducation

Journal of the Faculty of Technics and Technologies, Trakia University https://sites.google.com/a/trakia-uni.bg/artte/

The equation gives column height and for a cohobation column it is the sum of the cube height $\left(H_{1}\right)$, the distance between the upmost tray and the top of the column $\left(\mathrm{H}_{3}\right)$ and the product $\left(n_{D}-1\right)$.h, where $n_{r}$ is the actual number of trays and $h$ - the distance between the trays; here the distance between the individual parts of the column $\left(\mathrm{H}_{2}\right)$ is neglected since the cohobation column is the depleting part of a rectification column.

\section{RESULTS AND DISCUSSION}

The thermodynamic diagrams illustrating the vapor-liquid equilibrium of the system dill oil (grass and fruits) - water are presented in Figure 1.

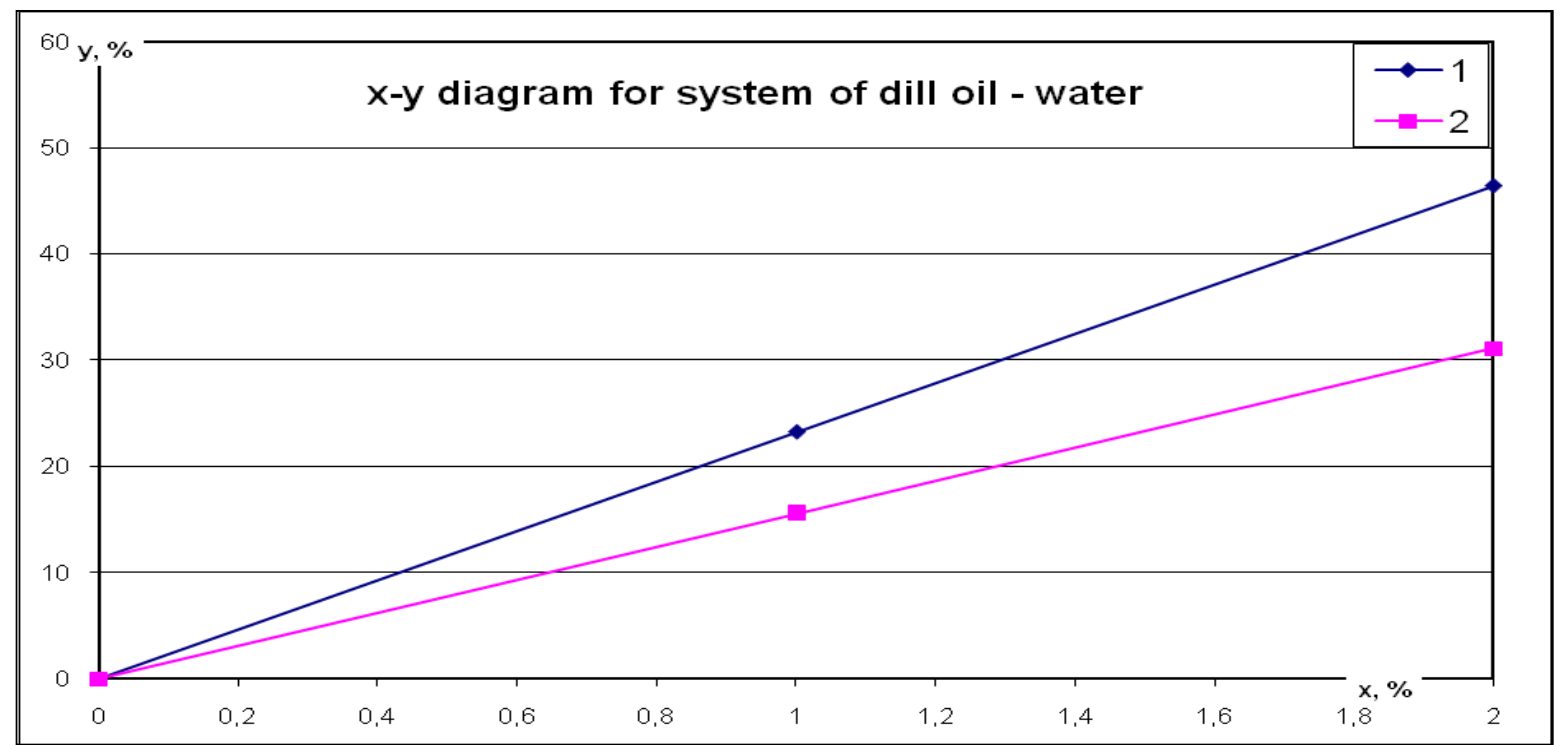

Figure 1. Thermodynamic diagram of the vapor-liquid equilibrium of the system essential oil - water

1 - for the system dill grass oil - water; 2 - for the system dill fruit oil - water

Based on the graphical dependencies, equations for calculation of the concentration of the vapor phase in the system essential oil - water were derived which were as follows:

- for essential oil from dill grass $-y=23,2016 . x+9.10-15$;

- for essential oil from dill fruits $-y=15,551 . x-5.10-15$;

where:

$y$ is the concentration of the vapor phase for the system essential oil - water, mol. \%;

$\mathrm{x}$ is the concentration of the liquid phase for the system essential oil - water, mol. \%.

Using the equations derived the concentration in the concentration in the vapor phase was calculated. It can be seen from the data that for the coefficient multiplying the liquid phase concentration of the system essential oil from dill grass - water is higher than the theoretically calculated one for the system essential oil from fill fruits - water which is due to the different components contained in the oils. This confirmed the data obtained for the other systems essential oil - water with different oils [16].

On the basis of the graphical dependencies obtained for the vapor-liquid mixture in the system essential oil from dill (grass and fruits) - water, the step-shaped line showing the number of theoretical trays of the column was drawn.

It was assumed for the calculation of the actual number of trays that $\eta=0,6$.

The results obtained from the calculation of the actual number of trays are presented in Table 2 and the height of the cohobation column in Table 3.

IRTIIE Vol. 6, No. 1, 2018 ISSN 1314-8788 (print), ISSN 1314-8796 (online), doi: 10.15547/artte.2018.01.006 
Table 2. Determination of the theoretical and actual number of trays

\begin{tabular}{|l|c|c|c|c|}
\hline Denotation & Dimension & $\begin{array}{c}\text { Minimal } \\
\text { concentration, } \\
\% \text { mol }\end{array}$ & $\begin{array}{c}\text { Medium } \\
\text { concentration, } \\
\% \text { mol }\end{array}$ & $\begin{array}{c}\text { Maximal } \\
\text { concentration, } \\
\% \text { mol }\end{array}$ \\
\hline \multicolumn{5}{|c|}{ Dill grass } \\
\hline $\mathrm{n}_{T}$ & number & 46 & 50 & 52 \\
\hline $\mathrm{n}_{\mathrm{D}}$ & number & 77 & 81 & 87 \\
\hline $\mathrm{n}_{\mathrm{T}}$ & number & 45 & 48 & 50 \\
\hline $\mathrm{n}_{\mathrm{D}}$ & number & 75 & 80 & 81 \\
\hline
\end{tabular}

Table 3. Determination of the height of the cohobation column

\begin{tabular}{|c|c|c|c|c|}
\hline Denotation & Dimension & $\begin{array}{c}\text { Minimal } \\
\text { concentration, } \\
\% \mathrm{~mol}\end{array}$ & $\begin{array}{c}\text { Medium } \\
\text { concentration, } \\
\% \text { mol }\end{array}$ & $\begin{array}{c}\text { Maximal } \\
\text { concentration, } \\
\% \text { mol }\end{array}$ \\
\hline $\mathrm{H}_{1}=(2,5 \div 3) \mathrm{h}$ & $M$ & \multicolumn{3}{|c|}{0,125} \\
\hline $\mathrm{H}_{2}=(2 \div 2,5) \mathrm{h}$ & $\mathrm{M}$ & \multicolumn{3}{|c|}{0,1} \\
\hline \multicolumn{5}{|c|}{ Dill grass } \\
\hline$\left(n_{D}-1\right) h$ & $\mathrm{M}$ & 3,80 & 4,00 & 4,30 \\
\hline $\mathrm{H}_{\text {total }}$ & $\mathrm{M}$ & 4,03 & 4,23 & 4,53 \\
\hline \multicolumn{5}{|c|}{ Dill fruits } \\
\hline$\left(n_{D}-1\right) h$ & $M$ & 3,70 & 3,95 & 4,00 \\
\hline $\mathrm{H}_{\text {total }}$ & $M$ & 3,93 & 4,13 & 4,23 \\
\hline
\end{tabular}

It can be seen from these data that the height of the cohobation column was highest at the maximal concentration of the distillation waters regardless whether essential oil from dill oil or dill fruits is processed.

The analysis of the results presented showed that the highest number of actual trays was the highest at the maximal concentration of the distillation waters. It should be noted also that the number of trays at medium and maximal concentrations are close to each other which can be explained with the small difference between the concentrations in the distillation waters.

The height of the cohobation column determined on the basis of the calculations above turned out to be between 3,93 and 4,53 m. The values obtained for the two kinds of oils are commensurable and in comparatively in narrow margins. This is due to the close values of the components identified in the oils.

\section{CONCLUSION}

The composition of the essential oil has significant effect on the drawing of the thermodynamic phase diagrams of the systems essential oil - water, as well as on the deriving of the equations for these systems but not on the height of the cohobation column determined on the basis of these diagrams.

\section{REFERENCES}

[1] Akteryan S., Atanasova T. (2006). Definition of Mass Transfer Parameters of Cohobating Column, Designed for Manufacturing of Distillation Waters from Essential Raw Material, Containing Anethole. Proceedings of conference Dendrariyu dalynevostoch NII year 100, October, Khabarovsk, 2006, pp. 234-237. 


\section{ARTIIE \\ Ipplied Researrothes in Technics, Technologies and Bductition Journal of the Faculty of Technics and Technologies, Trakia University https://sites.google.com/a/trakia-uni.bg/artte/}

[2] Anoshin M. (1970). Theoretical fundamentals of mass transfer processes. Food industry, Moscow, 1970.

[3] Georgiev, E., Stoyanova A.. (2006). Directory for experts of the flavoring industry. BNAEOPC, Plovdiv, 2006.

[4] Dimov M., Dobreva K., Damyanova S., Stoyanova A. (2017). Chemical composition, antioxidant and antimicrobial activities of dill essential oils (Anethum graveolens L.). Annual of Assen Zlatarov University, Burgas, Bulgaria, v. XLVI, 2017, (in press).

[5] Kafarov W. (1962). Fundaments of mass transfer, Moscow, Highs school, 1962.

[6] Kogan V., Friedman V. (1975). Methodology for calculation of vapor - liquid phase equilibrium of the two- and multicomponent systems. Leningrad Goshizdat, 1975.

[7] Kogan V., Fridman V., Kafarov W.. (1966). Equiblrium of liquid and vapor MoscowLeningrad, Sceince, 1966.

[8] Ryvkin S., Aleksandrov A. (1988). Thermodynamic properties of water and water vapor, Sofia, Technique, 1988.

[9] Sendov S. (1988). Heat and mass transfer, Sofia, Technique, 1983.

[10] Sidorov I., Turysheva N., Faleeva L., Yasyukevich E. (1984). Technology of Natural Essential Oil and Synthetic Aroma Products, Light and Food Industry, Moscow, 1984.

[11] Sokolynikov N., Kondratskiy A. (1958). Technology of Essential Oil Proceedings "Pishtepromizdat", Moscow. 1958.

[12] Stabnikov W. (1969). Distillation and rectification ethyl spirt, Moscow, Food industry, 1969.

[13] Stabnikov W., Barancev W. (1983). Process and apparatus in food industry, Moscow, 1983.

[14] Stoyanova A., Georgiev E. (2007). Technology of essential oils, Plovdiv, UFT, 2007.

[15] Tasheva S. (2005). Investigation of energy efficacy of cohobation installations. PhD, TUSofia, 2005.

[16] Tasheva S. (2014). Mass-transfer processes by cohobation of distillation waters and extraction of essential oils in raw material. DSc. Plovdiv, UFT, 2014.

[17] Chipiga A. (1981). Information Technologist of Essential Oil. Proceedings "Light and food industry, Moscow. 1981. 